\title{
Judicialização da Vida na Contemporaneidade
}

Life Judicialization In Contemporaneity

Judicialización De La Vida En La

Contemporaneidad

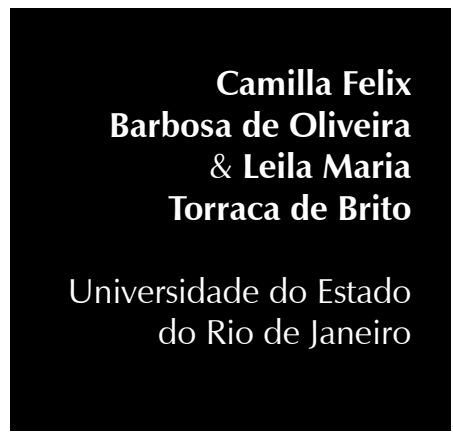


Resumo: Este artigo visa a empreender um estudo sobre o fenômeno da judicialização da vida na contemporaneidade. Por judicialização, compreende-se o movimento de regulação normativa e legal do viver, do qual os sujeitos se apropriam para a resolução dos conflitos, reproduzindo uns com os outros o controle, o julgamento e a punição das condutas. Nesse sentido, objetiva-se analisar os efeitos dos discursos e das práticas jurídicas sobre as subjetividades, ou seja, sobre as formas de os sujeitos se relacionarem, experimentarem e conceberem suas vidas. Para tanto, utilizar-se-á como disparadores leis, políticas e ações relacionadas à alienação parental e ao bullying, evidenciando as lógicas patológicas e judicializantes que as embasam e suas aproximações com o campo psi. Por fim, propõe-se que a Psicologia esteja em permanente reflexão ético-política, a fim de fomentar a construção de práticas psi inovadoras, que rompam os aprisionamentos produzidos pelo movimento de judicialização e que inaugurem desvios a serviço da valorização da vida.

Palavras-chave: Subjetividade. Bullying. Síndrome da alienação parental. Processos sociais.

Abstract: This article aims to study the phenomenon of contemporary judicialization of life. By judicialization it can be understood the movement of legal and normative regulation of living, which is appropriated by the individuals for the resolution of conflicts, which reproduces to each other the control, judgment and punishment of conducts. In this sense, the objective of this work is to analyze the effects of discourses and legal practices over subjectivities, ie, the way individuals relate experience and conceive their lives. Thus, laws, policies and actions related to parental alienation and bullying will be used as triggers, highlighting the pathological and judicial logics that are their basis and how close they are to psychology. Finally, it is proposed that psychology is in constant ethical-political reflection in order to foster the construction of innovative psi practices, which break the imprisonment produced by the movement of judicialization and create new paths for life improvement.

Keywords: Subjectivity. Bullying. Parental alienation syndrome. Social processes.

Resumen: Este artículo tiene la intención de emprender un estudio sobre el fenómeno de la judicialización de la vida en la contemporaneidad. Por judicialización, se comprende el movimiento de regulación normativa y legal del vivir, del cual los sujetos se apropian para la resolución de los conflictos, reproduciendo unos con otros el control, el juicio y el castigo de las conductas. En ese sentido, se objetiva analizar los efectos de los discursos y de las prácticas jurídicas sobre las subjetividades, o sea, sobre las formas de cómo los sujetos se relacionan, experimentan y conciben sus vidas. Para eso, han de utilizarse como disparadores leyes, políticas y acciones relacionadas a la alienación parental y al bullying, evidenciando las lógicas patológicas y judicializantes que las sustentan y sus aproximaciones con el campo psi. Por fin, se propone que la Psicología esté en permanente reflexión ético-política, con el fin de fomentar la construcción de prácticas psi innovadoras, que rompan los aprisionamientos producidos por el movimiento de judicialización y que inauguren desvíos a servicio de la valorización de la vida.

Palabras clave: Subjetividad. Bullying. Síndrome de la alienación parental. Procesos sociales.

Em 2010, foi sancionada no Brasil a Lei federal no 12.318/2010, que dispõe sobre a alienação parental, considerada interferência na formação psicológica da criança ou do adolescente, promovida por um dos pais ou pelos que a tenham sob sua autoridade ou guarda. Na lei, esses atos são concebidos como abuso moral, pois feririam direitos fundamentais à convivência familiar saudável e prejudicariam a integridade psicológica. Diagnosticada a alienação, a intervenção judicial poderá ser desde uma advertência ao alienante até a suspensão da sua autoridade parental.

Concomitantemente, assistimos, nos últimos anos, ao boom do fenômeno chamado bullying. Sem uma lei federal, diversos
Estados do País têm criado e aprovado legislações estaduais que se destinam a instituir políticas antibullying nas escolas, com programas de ação interdisciplinar e participação de especialistas no tema, englobando ainda responsáveis, alunos e professores nos métodos preventivos.

As definições legais, em geral, concebem o bullying como prática de assédio moral com ocorrência intencional e repetitiva de atos de violência física e psicológica, visando a intimidar, agredir, humilhar, causar dor e sofrimento à vítima, inclusive por meio da exclusão social, em uma relação desigual de poder. O ciberbullying incluiria os mesmos atos praticados através da internet ou de outro meio digital (Lei no 14.651/2009, Lei no 6.084/2011). 
A partir dessa exposição, podemos supor que tais fenômenos se entrecruzam em seus caminhos, indicando a forte tendência, que notamos na atualidade, de reduzir questões da esfera político-social a concepções individualizantes, enquadrando desvios e tensões no processo de judicialização do viver. Nessa lógica, conflitos familiares, mudanças geradas pelo divórcio e o modo de os sujeitos elaborarem esses acontecimentos são destituídos de sua variabilidade e enquadrados na esfera da alienação parental. De modo semelhante, os mais diversos atos são passíveis de serem descritos como bullying, sendo iminente o risco de os sujeitos o sofrerem ou praticarem em suas relações cotidianas.

Destarte, tendo como disparadores legislações, conceitos e políticas relacionados à alienação parental e ao bullying, o presente artigo visa a empreender uma análise do fenômeno da judicialização da vida na contemporaneidade. Compreendemos por judicialização o movimento de regulação normativa e legal do viver, do qual os sujeitos se apropriam para a resolução dos conflitos cotidianos. Atravessados pelo Poder Judiciário, não somente se recorre a ele como também se incorporam e se legitimam seus modos de operação, reproduzindo-se o controle, o julgamento e a punição das condutas, em prol - assim é justificado da inviolabilidade dos direitos, do melhor interesse, da proteção e do bem-estar de algumas vidas.

\section{O caso bullying}

São Paulo, 2012. "Garoto que sofria bullying por causa da música Florentina, do Tiririca, poderá mudar de nome":

Insatisfeito com as brincadeiras e chacotas dos colegas de escola, um garoto de 17 anos conseguiu na Justiça o direito de retirar a palavra 'Florentino' de seu nome. O garoto sofria bullying porque os outros alunos a associavam à música Florentina, interpretada pelo humorista Tiririca... $\mathrm{O}$ bullying foi constatado pela psicóloga da escola em que o garoto estuda... Em sua decisão, o desembargador João Pazine Neto, do TJSP (Tribunal de Justiça de São Paulo), disse que "é fato notório e público que o nome 'Florentino' faz parte do repertório de uma música do humorista 'Tiririca', música essa de caráter cômico, destinada à zombaria e gracejo que em nada dignifica o sobrenome mencionado."... Para o desembargador, o fato de o garoto estar na adolescência e em fase escolar agrava o quadro, pois "a zombaria pode causar graves danos à sua personalidade, devendo, portanto, ser reprimido qualquer fato que possa potencializar a zombaria da escola a the causar constrangimentos". (UOL Educação, 2012, itálicos nossos).

Insultos, comentários pejorativos, agressões, intimidação, exclusão social: é cada vez mais abrangente o rol de práticas que se encaixam na categoria bullying (Lei no 14.651/2009, Lei no 6.084/2011). Tendo como eixo central a questão da violência nas escolas, esse fenômeno tem sido intensamente difundido em um formato que o reveste de uma efetividade inegável, afirmando sua existência através de inúmeros exemplos cotidianos que ilustram o que é o bullying e que servem de parâmetro para identificar casos semelhantes. Assim, tem-se favorecido a acrítica e expansiva apropriação do conceito em nosso meio.

Situações antes vividas como banais, corriqueiras, são, atualmente, interpretadas com base em outras significações, como no exemplo supracitado. Há alguns anos, apelidar o colega ou zoar seu nome era visto como brincadeira entre crianças e adolescentes, que, se por alguma especificidade necessitassem de uma atenção diferenciada, esta não ultrapassaria o espaço escolar. Hoje essas questões são resolvidas na Justiça, pois já não se fala em brincadeiras, mas em violências que agridem e traumatizam, devendo assim 
A mãe relatou sua indignação e surpresa, já que, na época da briga, que soube pelo filho, não recebeu qualquer contato da escola e, assim, deu o assunto por encerrado, até receber a intimação policial meses depois (Andrade, 2011). ser combatidas, denunciadas e punidas.

É interessante notar a ênfase ao "desolamento causado por suas consequências e a inquestionável necessidade de intervenção via imperativos morais" (Antunes \& Zuin, 2008, p.35), que acentua os danos psicológicos sofridos pela vítima e as leis de proteção e combate a tal violência. As ciências do Direito e da Psicologia são, assim, chamadas a falar, a intervir, a diagnosticar e a prevenir essas questões. No caso exemplificado, vimos que o bullying foi constatado pela psicóloga da escola e que a decisão do Desembargador de autorizar a mudança de sobrenome do adolescente teve como justificativa a importância da eliminação de qualquer fator de constrangimento que pudesse desencadear algum dano a sua personalidade em desenvolvimento; dupla presença da Psicologia: tanto no diagnóstico da situação quanto na base da decisão para resolver o problema.

No que tange ao bullying, as ciências endossam a ideia de que o ato pode não deixar marcas físicas e visíveis, mas acarretaria sérios efeitos psicológicos para as vítimas. Uma hipótese é a de que o agressor também já foi uma vítima de bullying e, por causa dos danos em sua personalidade, reproduz as agressões. Diante de tantos traumas, culpas e interioridades, está montado o cenário para a intervenção do psicólogo.

Nesse sentido, a atenção é centrada no indivíduo, produzindo sua vitimização e/ ou culpabilização, buscando justificativas em seu interior e ignorando os processos socio-históricos que engendram modos de ser na contemporaneidade. Para Antunes e Zuin, essas formas individualizantes e normativas de concebermos e classificarmos os fenômenos como bullying "denunciam, ainda que pelas lacunas, que tal conceito faz parte de uma ciência instrumentalizada e a serviço da adaptação das pessoas para a manutenção de uma ordem social desigual" (2008, p.35).

No contexto escolar, o encaminhamento para tais conflitos tem sido menos a sala da direção, da coordenação, e cada vez mais a delegacia. Ademais, não só a escola tem ido à polícia como também esta tem adentrado pelo seu espaço. Exemplos cotidianos não faltam: no Rio de Janeiro, policiais militares patrulham escolas da rede estadual, graças a um convênio firmado entre as Secretarias Estaduais de Educação e Segurança. O objetivo? Proteger professores e alunos, impedir a venda e o consumo de drogas e, é claro, combater o bullying. Os benefícios? O governador do Estado responde: "A presença do policial vai agregar valor à escola, pais e professores passarão a ter outro nível de tranquilidade" (Quaino, 2012).

Outro exemplo revelador dessa estreita parceria entre escola e polícia, um caso levado à delegacia despertou estranhamento devido a sua condição extrema: a intimação de um menino de cinco anos para depor, após queixa da professora, por ele mordida quando apartava uma briga na classe. Ao ser veiculada, a notícia já informava que o delegado que intimou a criança admitiu o erro e havia repassado o caso para o Conselho Tutelar. A mãe relatou sua indignação e surpresa, já que - na época da briga, que soube pelo filho - não recebeu qualquer contato da escola e, assim, deu o assunto por encerrado, até receber a intimação policial meses depois (Andrade, 2011).

Nas situações mencionadas, é sobressalente a ausência de qualquer tentativa de diálogo entre família e escola, recorrendo-se de imediato à intervenção da polícia e de outras instâncias do Judiciário. A ênfase pouco mudou: continua-se atentando para a indisciplina, a dificuldade, a inadequação e para o que é visivelmente identificado como desvio, transgressão ou doença. Porém, 
outras formas de lidar com essas questões estão se difundindo, principalmente as que dificultam uma analítica contextual, como as práticas de judicialização dos conflitos vivenciados.

\section{O caso SAP}

A expressão síndrome da alienação parental (SAP) foi cunhada na década de 80 pelo psiquiatra norte-americano Richard Gardner para referir-se ao processo de lavagem cerebral ou treinamento realizado pelo genitor alienante para difamar a imagem do outro responsável, acometendo crianças e adolescentes cujos pais vivem em situação de litígio (Sousa \& Brito, 2011). Na visão do médico, essa seria, principalmente, uma postura vingativa e de ataque ao excônjuge, fruto de má elaboração do luto da separação, em que o filho é usado como meio para agredir o ex-parceiro. No Brasil, temos em vigor a Lei federal no 12.318/2010, e designamos o dia 25 de abril como o Dia Internacional da Conscientização da Alienação Parental.

Falar mal do pai ou da mãe para os filhos é um comportamento comum, principalmente depois da separação. Usar a criança para atingir a outra parte, entretanto, pode provocar distúrbios na vida de todos os envolvidos. A 'síndrome da alienação parental' é um assunto tão sério no mundo que ganhou até um dia especial de conscientização.

Desde agosto de 2010, o Brasil conta com uma legislação específica para combater essa prática nociva à formação de crianças e adolescentes. De acordo com a lei, alienação parental ocorre quando há 'interferência na formação psicológica promovida ou induzida por um dos genitores ou pelos que tenham a criança sob sua autoridade'...

Pai de um menino de um ano e nove meses, um contador de 28 anos... afirma que a situação se agravou quando a ex-mulher descobriu o envolvimento dele com outra pessoa. 'Desde dezembro, ela só permite que eu veja meu o filho na casa dela e por um período determinado. Meus pais e minhas irmãs também não conseguem vê-lo. É uma situação vexatória... Estou fazendo tratamento psicológico para poder suportar', desabafou. (Rodrigues 2012, itálicos nossos)

No caso em tela, observamos o predomínio das lógicas patológica e judicializante na abordagem dos conflitos relacionais, concebendo-os em termos de distúrbio a ser diagnosticado e a infração a ser combatida. A situação do rompimento conjugal, com as dificuldades que acarreta, em especial no que tange às decisões sobre guarda e cuidado dos filhos, tem gerado um elevado número de questões parentais levadas à Justiça, cada vez mais sob a alegação de alienação parental.

De acordo com a lei, a alienação ocorre quando o guardião interfere negativamente na formação psicológica da criança ou do adolescente, promovendo um dos seguintes atos:

I - realizar campanha de desqualificação da conduta do genitor no exercício da paternidade ou maternidade;

II - dificultar o exercício da autoridade parental;

III - dificultar contato de criança ou adolescente com genitor;

IV - dificultar o exercício do direito regulamentado de convivência familiar;

$\mathrm{V}$ - omitir deliberadamente a genitor informações pessoais relevantes sobre a criança ou adolescente, inclusive escolares, médicas e alterações de endereço;

VI - apresentar falsa denúncia contra genitor, contra familiares deste ou contra avós, para obstar ou dificultar a sua convivência com a criança ou adolescente; VII - mudar o domicílio para local distante, sem justificativa, visando a dificultar a convivência da criança ou adolescente com o outro genitor, com familiares deste ou com avós. (Lei no 12.318/2010)

A partir da análise de publicações e de artigos relacionados à SAP, Sousa (2009) constatou que os discursos reforçam uma visão individualista e punitiva da situação: o 
genitor alienador favoreceria a síndrome no filho alienado e o prejudicaria. O alienador, portanto, seria identificado como causa do problema, devendo ser coibido em suas ações. Privilegiado esse enquadre, pouco se aborda os aspectos sociais, culturais e legais ligados à vivência da separação, como as relações de gênero, a divisão dos papéis parentais, o predomínio da modalidade unilateral de guarda, as mudanças nas famílias e nos relacionamentos contemporâneos, dentre outros.

\section{Sousa destaca a forma como o conceito da SAP} tem se disseminado, propagando-se a ideia de ser essa uma realidade inquestionável. Com tal difusão, que ressalta seu caráter patológico e prejudicial, passamos a atentar para seus indícios, compartilhando casos, destinando um dia de conscientização, identificando seus efeitos e recorrendo ao aparelho jurídico para a sua punição.

A justificativa que permeia os discursos ressalta a necessidade de proteção daqueles que sofrem com o afastamento de um dos pais em virtude da manipulação do outro. A ideia de que os danos seriam, sobretudo, psicológicos demanda o saber-fazer psi. Para alguns, a alienação parental deveria adquirir o status de crime (Paulino, 2012), sendo então regulada por legislações e resolvida no Judiciário, sem se descartar a participação da Psicologia. De acordo com a Lei no 12.318/2010, compete ao psicólogo perito identificar a alienação, avaliar as personalidades das vítimas e culpados, além das perdas e traumas dela decorrentes, fornecendo, através do laudo psicológico, subsídios que legitimem e revistam de cientificidade as decisões judiciais.

Dentre as medidas aplicáveis ao genitor alienante, a lei prevê desde advertências, multas e acompanhamento psicológico até inversão da guarda e suspensão da autoridade parental, tendo como efeito o afastamento entre a criança e o alienador. Acerca disso, ressaltamos a seguinte problemática:

A lista de medidas que podem ser adotadas parece sugerir que, agora, o Estado é quem possui o direito de alienar um dos pais da vida da criança. Nesse sentido, questionase se teorias psicológicas dariam respaldo a tais medidas. Estar-se-ia desconsiderando os prejuízos emocionais causados à criança, que bruscamente será afastada do genitor com quem convive e com quem mantém fortes ligações? (Sousa \& Brito, 2011, p.276)

Continuaremos a olhar tais questões por meio dos vieses patológicos e judiciais? Priorizaremos a identificação do culpado, a fim de coibir seus atos e preservar suas vítimas? A lei da alienação parental reforça a forma punitiva de se abordar os conflitos, apesar de trazer em seus discursos uma pretensa humanização da Justiça, que, ao legislar sobre tais atos, estaria zelando pela integridade humana e pelos direitos subjetivos. Assim, a lei prevê a aplicação da guarda compartilhada (prevista como sanção, vale ressaltar) para que o filho tenha garantida a convivência com ambos os pais e em determinação de acompanhamento psicológico para o alienador, já que este se encontra em um estado de crise fruto da má elaboração das dificuldades conjugais.

O que questionamos é se de fato a lei consegue despir-se da lógica punitiva e patológica que perpassa o conceito da SAP. Incluir, por exemplo, o tratamento psicológico como uma medida humanizada não faz com que ela perca sua condição de infração, mas faz com que o acompanhamento psicológico adquira o sentido de sanção, de sentença judicial determinada, sem uma escolha efetiva do sujeito.

Sob esse prisma judicializante, o psicólogo torna-se um profissional indispensável na Justiça, competindo a ele, sobretudo, analisar 
os indivíduos de acordo com as leis que tratam de aspectos emocionais e subjetivos. Ademais, a ideia de que devemos estar vigilantes a qualquer indício de SAP que coloque a criança em risco, a fim de afastála, vai contra a perspectiva de valorização de ambos os pais no cuidado dos filhos presente na guarda compartilhada, tornando assim conflitantes as referidas leis.

A guarda compartilhada requer que se deixe de lado a procura do genitor que apresente melhores condições para deter a guarda dos filhos para se pensar em uma atuação que auxilie os pais no compartilhamento da guarda de filhos comuns... Entretanto, no contexto nacional, o clamor por punição dos denominados genitores alienadores logo fez desvanecer essa expectativa quanto à atuação dos psicólogos nos juízos de família, realocando-se esses profissionais no lugar daqueles que devem privilegiar a elaboração de avaliações, visando, agora, à apuração da existência, ou não, da alienação parental... Assim, da ênfase na participação de ambos os pais na educação dos filhos, independentemente de sua situação conjugal, fixam-se as lentes no suposto perigo que um dos pais pode representar para a criança. (Sousa \& Brito, 2011, p.279)

\section{Humanização da Justiça ou judicialização do humano?}

O que há em comum entre os casos de SAP e bullying? Quais conceitos e verdades disseminam? Que efeitos produzem sobre as relações e modos de vida?

Primeiramente, são fenômenos recentes, com ampla repercussão midiática, divulgados de modo a favorecer a apropriação naturalizada e acrítica, reforçando a base na ordem jurídica e o respaldo assegurado pelas leis. Ambos teriam como foco questões relacionais difíceis, que produzem sofrimento ou prejuízo, emergindo sob a forma de crime a ser combatido. Seus efeitos? Sérios danos - em especial psicológicos - para suas vítimas. Tratadas como violências contempladas por legislações específicas, essas práticas que se dão no cotidiano das relações têm agora um destino certo: o sistema judiciário. São, por conseguinte, dois processos da atualidade que ilustram o fenômeno da judicialização da vida.

Conforme sinalizamos, tais casos, analisados à luz dos vieses jurídico e psi, têm produzido a naturalização de processos da existência reduzidos ao nível individual do crime e da culpa, sendo cada vez mais desfocado o horizonte socio-político que os funda e legitima. Destarte, temas amplos e complexos, como violência, educação, relacionamentos, famílias e parentalidade são abordados de modo fragmentado, desconsiderando-se toda a rede coletiva que os tecem.

Reproduzido o imperativo de que a felicidade é um direito individual ao alcance de todos, sofrer torna-se absolutamente evitável e injustificado, a não ser que seu fator desencadeante independa do nosso controle e previsão. Em tais casos, não há dúvida de que "alguém tem de ser culpado, e deve haver um réu ligado à culpa. Todo caso de sofrimento é potencialmente, até que se prove o contrário, um caso de vitimização - e qualquer pessoa que sofra é (ao menos potencialmente) uma vítima". (Bauman, 2009, p. 66)

Nesse sentido, se o litígio conjugal tem dificultado o exercício do papel parental, automaticamente buscar-se-á identificar o genitor alienante, ou, caso um aluno vivencie problemas nas relações escolares, o primeiro passo deve ser apontar o responsável pelo bullying. Para Bauman, nessa cultura da vitimização, que complementamos como sendo também a cultura da judicialização, a qualquer tempo

uma pessoa, ou sujeito de direito, pode ser processada, e não faltam especialistas jurídicos ávidos por assumir a causa do sofredor. Além dos benefícios materiais que os sofredores e seus advogados 
podem obter a partir de um veredicto positivo de um tribunal, a suposta vitimização será então legitimamente confirmada. (2009, p. 66)

Assim, demanda-se que a Justiça legisle sobre todos os aspectos do viver. Sob a justificativa de humanização do sistema jurídico, leis e processos passam a regular danos, afetos, interferências, humilhações. Entretanto, temos percebido que essa humanização que pretende garantir o bemestar e a proteção dos direitos individuais é a mesma que perpetua uma lógica punitiva, enquadrando algumas vidas no banco dos réus. Contraditoriamente, em favor do ser humano e de seus direitos, clama-se por mais intervenções jurídicas, práticas de controle, encarceramento e punição, alimentando a judicialização de nossas vidas e "fazendo de cada um de nós que aceita essa condição ora juiz, ora acusador, algoz e vítima" (Augusto, 2009, p.13).

Com base em uma lógica dicotômica que separa o bem do mal, o agressor da vítima, o cidadão do criminoso, o inocente do culpado, reforça-se a segregação social e a culpabilização do indivíduo, além de políticas penais repressivas, violentas e estigmatizantes. Tal lógica, para Bicalho, Kastrup e Reishoffer,

faz parte de uma complexa rede de produção subjetiva que incorpora elementos autoritários, clamando por penas mais severas, pela redução da maioridade penal, constrói novos padrões de segregação urbana com o aumento dos muros, instalação de câmeras e circuitos internos e até cercas elétricas. Esses novos padrões subjetivos 'permitirão a suspensão dos princípios éticos, dos direitos constitucionais e das garantias legais, comprometendo as bases democráticas das sociedades ocidentais'. (2012, p. 61)

Apesar de constitucionalmente vivermos em um Estado Democrático de Direito, fundamentado na inviolabilidade da dignidade e dos direitos humanos, prevalece uma ordem social baseada no medo, que legitima a violação dos direitos das classes perigosas. Equiparadas a monstros, reservamos-lhes o descaso, o controle e a criminalização de suas vidas. Vidas delinquentes, anormais e perigosas, tornadas indignas de sua humanidade e direitos fundamentais, vidas que, "em nome de outras vidas, podem e devem ser manipuladas, descartadas, monitoradas, encarceradas, exterminadas, podem ter seus direitos suspensos e, mesmo, eliminados" (Coimbra, 2009, p.84).

O outro será sempre um risco em potencial do qual é preciso se proteger. Assim, justificamos o afastamento da mãe alienante ou a entrada da polícia nas escolas para controlar ações violentas. Individualizada a questão, não somente as intervenções recaem sobre o indivíduo como também, de acordo com Augusto, "o ato de julgar ganha relevância como prática da democracia participativa, que introjeta a necessidade de punição como algo indispensável à vida de todos, como ato necessário para o bem comum e para o bem de cada um, de cada cidadão de bem" (2009, p.19).

Com esse olhar individualizante e punitivo, temos gerido as vidas, incentivado a participação dos cidadãos nos julgamentos, produzido leis e demandado medidas tutelares que contemplem os mínimos aspectos do viver. Nesse processo, compreendido como judicialização, tudo deve ser controlado, recompensado ou punido, passando pelo Judiciário e pelo rol de profissionais que ali estão.

Elegemos mediadores e solucionadores para os conflitos, confiando na garantia dos saberes fornecidos pelos especialismos. Em suma, espera-se que a justiça seja feita, que ela forneça uma solução, uma sentença, uma reparação, uma vítima e um culpado. Acredita-se na sua imparcialidade 
Assim, a vida é decidida em um tribunal, onde, na maior parte das vezes, não se procura conhecer a história de vida do sujeito" (Correia \& Nunes, 2011). e capacidade de identificar a verdade e de decidir com base nela, tendo em vista que "a decisão jurídica é aquela que sabe qual das partes envolvidas no processo está com a razão. Assim, a vida é decidida em um tribunal, onde, na maior parte das vezes, não se procura conhecer a história de vida do sujeito" (Correia \& Nunes, 2011).

Vemos, portanto, que as práticas judiciárias continuam a definir tipos de subjetividades e a perpassar as formas de relação entre homem e verdade nas sociedades contemporâneas. As normas, leis, riscos, previsões e punições encontram-se enraizadas nos modos de vidas, em que cada um deve gerir sua existência impecavelmente e fiscalizar a gerência do outro, para o caso de ela apresentar alguma falha ou problema que demande uma intervenção jurídica.

Nesse sentido, também compreendemos a judicialização como a produção de subjetividades aprisionadoras, moralizantes, que vigiam e julgam a si mesmas e às demais, fortalecendo as biopolíticas que homogeneízam e delimitam os modos existenciais. Com o "panoptismo em nós" (Coimbra, 2009), vivemos em um campo de concentração a céu aberto, em que "uma tecnologia de controle opera não mais em lugares de confinamento fechados ou apartados de um fora, nem mesmo por uma delimitação territorial em relação ao centro, mas por uma administração do território por seus próprios habitantes" (Passeti como citado em Augusto, 2009, p.15)

A fim de incitar outras reflexões, explicitaremos a explicação de uma ministra do Superior Tribunal de Justiça (STJ) sobre a sentença que condenou um pai a indenizar a filha com duzentos mil reais por abandono afetivo, considerado como dano moral e com forte ênfase aos prejuízos psicológicos decorrentes de tal atitude. Segundo ela, na atualidade, cada vez mais a decisão judicial "analisa os sentimentos das pessoas, são novos caminhos e novos tipos de direitos subjetivos que estão sendo cobrados. Todo esse contexto resume-se apenas em uma palavra: a humanização da Justiça" (Justiça condena pai por abandono afetivo, 2012), ou, diríamos sob outra perspectiva, a judicialização da vida humana.

\section{Considerações finais}

O psicólogo baseará seu trabalho no respeito e na promoção da liberdade, da dignidade, da igualdade e da integridade do ser humano, apoiado nos valores que embasam a Declaração Universal dos Direitos Humanos.

O psicólogo trabalhará visando a promover a saúde e a qualidade de vida das pessoas e das coletividades e contribuirá para a eliminação de quaisquer formas de negligência, discriminação, exploração, violência, crueldade e opressão. (Conselho Federal de Psicologia, 2005, p. 7)

Esses são dois dos preceitos fundamentais do Código de Ética Profissional do Psicólogo. Primeiramente, importa destacar que sua construção visou a contemplar a diversidade que configura o exercício da profissão, pautando-se no princípio de se constituir mais como um instrumento de reflexão do que como um conjunto de regras pré-definidas.

O incentivo à reflexão: acreditamos ser esse um fator crucial para a análise crítica de nossos posicionamentos e atuações, considerando a ética, sobretudo, como o exercício de refletir sobre os efeitos do nosso saber-fazer cotidiano. Nesse sentido, ela pode ser considerada uma análise reflexiva do comportamento moral, sendo moral concebida como "um sistema de normas, princípios e valores, segundo o qual são regulamentadas as relações mútuas entre os indivíduos ou entre estes e a comunidade" (Vázquez, 1999, p.84). Esse sistema deve ser situado histórica e socialmente, na medida em que atende as demandas de um 
dado contexto em que se dão as relações humanas, constituindo-se como certo modo de regulação das condutas e de manutenção da ordem social.

Ao longo do trabalho, objetivamos fomentar essa análise reflexiva da judicialização da vida, problematizando os discursos e as ações que têm contribuído para a naturalização desse fenômeno. Os conceitos de bullying e de alienação parental foram utilizados como dispositivos de análise do nosso funcionamento social e jurídico, tendo em vista que reverberam as lógicas de individualização, de controle e de criminalização das condutas. Dessa maneira, buscamos deslocar o foco do indivíduo para as leis, instituições e práticas sociais que perpetuam uma ordem estabelecida e que tentam mascarar suas tensões e contradições, eximindo o Estado e a sociedade da implicação perante questões da esfera coletiva.

É assim que procedemos quando nos concentramos em identificar, prevenir e combater o bullying, ainda que para isso seja necessária a repressão policial, e obscurecemos "questões tais como processos de formação, trabalho e saúde dos educadores, financiamento da educação e modos de gestão da escola, dentre outras" (Heckert \& Rocha, 2011). Aplacamos os desvios e as tensões com a judicialização do viver, ressaltando as demandas de segurança, combate à criminalidade, medidas de proteção e garantia dos direitos de alguns cidadãos e vítimas.

De modo semelhante, justificamos as políticas de controle e as legislações que regulam as famílias, responsabilizando unicamente os pais pela saúde e pelo bem-estar de suas crianças e punindo-os por qualquer dano a elas causado. Engajados na luta contra a SAP, em seu duplo aspecto de infração e patologia, deixamos de priorizar, por exemplo, a criação de políticas públicas que garantam o acesso à saúde, educação e lazer para as crianças e adolescentes ou a busca de parcerias e redes de serviços que apoiem as famílias e incentivem a participação dos pais no cuidado dos filhos, em especial nas situações de litígio conjugal.

Ao considerarmos que um conflito ou um comportamento diferenciado do padrão pode vir a revelar algum dano/culpa, enquadrar-se em determinada lei, devendo ser julgado e punido/recompensado, dificultamos ao sujeito o exercício crítico, a implicação, a reflexão, o questionamento, a transformação e a apropriação de seus posicionamentos e atuações no mundo. Paradoxalmente, nós o responsabilizamos por um crime ou doença, mas insistimos em negar-lhe a possibilidade de reconhecer que não é um ser determinado ou vítima das circunstâncias, e sim, um sujeito social, político, ativo, criador e suscetível às mudanças e transformações que ocorrem a todo o tempo, em diferentes contextos e com múltiplas variáveis.

Atribuir imperativos morais, determinismos biológicos ou quaisquer outros à existência humana é desconsiderar toda forma de liberdade e responsabilidade do sujeito perante a vida. Se seu modo de ser e de estar no mundo é pré-determinado por essências invariáveis ou tem origens que ele não controla e desconhece, como requerer seu envolvimento na construção do viver particular e compartilhado?

Olhar o sujeito dessa forma é não considerálo como ser social, variado, criativo: como um ser de possibilidades. Desse modo, será fácil para o profissional psicólogo responder às demandas de soluções rápidas para as dificuldades e os sofrimentos humanos. Se a nossa perspectiva for limitante, não considerando o contexto em que o sujeito se encontra e as diversas relações que moldam sua existência, reproduziremos uma prática classificatória reducionista, que determina 
que a infração está acima de qualquer outra questão pertinente a sua narrativa de vida.

Temos observado que, legitimado pela diversidade de abordagens teóricas da profissão, o psicólogo pode vir a atuar de maneiras variadas, construindo, dentro dos parâmetros éticos, outros modos de intervenção. Questionamos aqui, porém, se continuaremos a reproduzir práticas que reforçam a ideia de que o problema está no sujeito em si, isolado, desconsiderando as questões políticas, sociais e culturais que permeiam sua vida. Ainda pautaremos nosso trabalho na dicotomia indivíduo/sociedade, tomando-os como polos opostos?

Vale frisar o papel da Psicologia na constituição das subjetividades contemporâneas, uma vez que suas produções discursivas e práticas incidem sobre temáticas existenciais, com a legitimação e o peso do seu status de ciência especialista na matéria humana. Dessa forma, não podemos dissociar o seu saber-fazer do caráter ético-político, ético na medida em que não é neutra e interfere nos modos como a vida se dá e como as relações se estabelecem; político, pois não pode deixar de assumir posicionamentos, o que a coloca sempre em uma "encruzilhada micropolítica fundamental". Guattari e Rolnik explicam:

Ou (seus profissionais) vão fazer o jogo dessa reprodução de modelos que não nos permitem criar saídas para os processos de singularização, ou, ao contrário, vão estar trabalhando para o funcionamento desses processos na medida de suas possibilidades e dos agenciamentos que consigam pôr para funcionar. Isso quer dizer que não há objetividade científica alguma nesse campo, nem uma suposta neutralidade na relação. (1996, p. 29)

A Psicologia, portanto, precisa estar atenta às determinações que impõe, aos modelos que reproduz, aos processos que congela e às subjetividades que consolida ou exclui. A depender da forma que considerar sua implicação ético-política com a sociedade, o psicólogo poderá atuar no sentido de homogeneizar as existências, reforçando a apropriação alienada e submissa das subjetividades que recebemos, ou buscar favorecer a relação de expressão e criação, "na qual o indivíduo se reapropria dos componentes da subjetividade, produzindo um processo que eu chamaria de singularização" (Guattari \& Rolnik, 1996, p.33).

Em consonância com Verani (1994), não podemos perder de vista os questionamentos e as análises sobre nossas práticas e implicações na (re)produção do poder punitivo e das vidas destituídas de sua condição humana para, a partir daí, tentarmos construir de fato o que nossa Constituição Federal afirma desde 1988: a existência do Estado Democrático de Direito, que tem como fundamento a dignidade humana e onde "todos são iguais perante a lei, sem distinção de qualquer natureza, garantindo-se aos brasileiros e aos estrangeiros residentes no País a inviolabilidade do direito à vida, à liberdade, à igualdade, à segurança e à propriedade" (Constituição da República Federativa do Brasil, 1988).

Fazendo referência, mais uma vez, aos preceitos do nosso Código de Ética Profissional, o psicólogo trabalhará para a promoção da saúde e dos direitos dos sujeitos e das coletividades, porém sem qualquer forma de violência, discriminação, crueldade ou opressão. Seja qual for a abordagem que adotar e o seu campo de intervenção, acreditamos que, com base na implicação e na reflexão ético-política de nossos discursos e ações, podemos criar coletivamente práticas psi inovadoras, que promovam desvios e inaugurem rupturas, a serviço da valorização da vida, e não da violência relativa às suas diversidades e multiplicidades, aos seus modos de expressão. 


\section{Camilla Felix Barbosa de Oliveira}

Mestranda do Programa de Pós-Graduação em Psicologia Social da Universidade do Estado do Rio de Janeiro,

Rio de Janeiro - RJ - Brasil.

E-mail: camilla-felix@hotmail.com

\section{Leila Maria Torraca de Brito}

Doutora em Psicologia pela Pontifícia Universidade Católica do Rio de Janeiro e Professora Associada da Universidade do Estado do Rio de Janeiro, Rio de Janeiro - RJ - Brasil.

Email: leila.torraca.brito@gmail.com.

Endereço para envio de correspondência:

Rua São Francisco Xavier, 524, $10^{\circ}$ andar, sala 10.001, bloco B, Maracanã. CEP: 20550-900. Rio de Janeiro, RJ.

\section{Referências}

Andrade, G. (2011, agosto). Garoto de cinco anos é intimado pela polícia por morder professora. Jornal Hoje. Recuperado em 08 março, 2012, de http://g1.globo.com/jornal-hoje/ noticia/2011/08/garoto-de-cinco-anos-e-intimado-pela-policiapor-morder-professora.html

Antunes, D., \& Zuin, A. (2008). Do bullying ao preconceito: os desafios da barbárie à educação. Psicologia e Sociedade, 20(1), 33-41. doi: http://dx.doi.org/10.1590/S010271822008000100004

Augusto, A. (2009). Juridicialização da vida ou sobrevida? Mnemosine, 5(1), 11-22.

Bauman, Z. (2009). Vida líquida. Rio de Janeiro: Jorge Zahar.

Bicalho, P. P. G., Kastrup, V., \& Reishoffer, J. C. (2012). Psicologia e segurança pública: invenção de outras máquinas de guerra. Psicologia e Sociedade, 24(1), 56-65. doi: http://dx.doi. org/10.1590/S0102-71822012000100007

Brasil. Constituição da República Federativa do Brasil. (1988, outubro). Recuperado em 6 de julho, 2012, de http://www. senado.gov.br/legislacao/const/

Brasil. (2010). Lei $n^{\circ}$ 12.318, de 26 de agosto de 2010. Lei sobre alienação parental. Brasília, DF: Autor. Recuperado em 26 julho, 2012, de http://www.planalto.gov.br/ccivil_03/ Ato20072010/2010/Lei/L12318.htm

Coimbra, C. M. B. (2009). Modalidades de aprisionamento: processos de subjetivação contemporâneos e poder punitivo. In R. T. Oliveira \& V. Mattos. Estudos de execução criminal: direito e psicologia. Belo Horizonte, MG: TJMG; CRP.

Conselho Federal de Psicologia. (2005). Resolução CFP n 010/05. Aprova o Código de Ética Profissional do Psicólogo. Brasília, DF.

Correia Jr., J. A., \& Nunes, C. M. (2011). A judicialização da vida: um movimento do/no contemporâneo. Recuperado em 19 abril, 2012, de http://judicializacaodavida.wordpress. com/2011/05/03/a-judicializacao-da-vida-um-movimentodono-contemporaneo/

Estado de Santa Catarina. Lei $n^{\circ} 14.651$, de 12 de janeiro de 2009. (2009). Fica o Poder Executivo autorizado a instituir o Programa de Combate ao Bullying, de ação interdisciplinar e de participação comunitária nas escolas públicas e privadas do Estado de Santa Catarina. Recuperado em 29 julho, 2012 de http://200.192.66.20/alesc/docs/2009/14651_2009_Lei.doc

Estado do Rio de Janeiro. Lei $n^{\circ} 6.084$, de 22 de novembro de 2011. (2011). Institui o programa de prevenção e conscientização do assédio moral e violência no âmbito do Estado do Rio de Janeiro. Rio de Janeiro, RJ. Recuperado em 26 julho, 2012, de http://alerjln1.alerj.rj.gov.br/contlei.nsf/c8aa09 00025 feef6032564ec0060dfff/9f6a44aadc4d3cb48325795
10063b100?OpenDocument Garoto que sofria bullying por causa da música Florentina, do Tiririca, poderá mudar de nome. (2012, 24 de abr.). UOL Educação. Recuperado em 03 agosto, 2012, de http://educacao.uol.com.br/noticias/2012/04/24/ garoto-que-sofria-bullying-por-causa-da-musica-florentina-dotiririca-podera-mudar-nome.htm

Guattari, F., \& Rolnik, S. (1996). Micropolítica: cartografias do desejo (pp. 25-55). Petrópolis, RJ: Vozes.

Heckert, A. L. C., \& Rocha, M. L. (2011). A maquinaria escolar e os processos de regulamentação da vida: embates e aprisionamentos. In Resumos do I Colóquio Internacional Michel Foucault: a judicialização da vida. Rio de Janeiro, UERJ. Recuperado em 29 abril, 2012, de http://foucaultjudicializacao. com.br/archives/category/resumos

Justiça condena pai por abandono afetivo. (2012, maio). G1 Brasil. Recuperado em 05 agosto, 2012, de http://g1.globo.com/brasil/ noticia/2012/05/justica-condena-pai-por-abandono-afetivo.html

Paulino, A. R. N. (2012, mar.). Brasil, um país onde a alienação parental é crime. (Palestra disponível em vídeo). Recuperado em 29 julho, 2012, de http://sindromealienacaoparental.blogspot. com.br/2012/03/brasil-um-pais-onde-alienacao-parental.html

Quaino, L. (2012, maio). Mais de 400 PMs armados vão patrulhar 90 escolas no RJ. G1 Rio de Janeiro. Recuperado em 07 agosto, 2012, de http://g1.globo.com/rio-de-janeiro/noticia/2012/05/ mais-de-400-pms-armados-vao-patrulhar-90-escolas-no-rj.html

Rodrigues, F. (2012, abril). Data lembra importância do combate à alienação parental com os filhos. G1 Araraquara e Região. Recuperado em 07 agosto, 2012, de http://g1.globo.com/sp/ araraquara-regiao/noticia/2012/04/data-lembra-importanciado-combate-alienacao-parental-com-os-filhos.html

Sousa, A. M. (2009). Síndrome da alienação parental: análise de um tema em evidência. (Dissertação de Mestrado). Instituto de Psicologia, UERJ, Rio de Janeiro.

Sousa, A. M., \& Brito, L. M. T. (2011). Síndrome de alienação parental: da teoria norte-americana à nova lei brasileira. Psicologia: Ciência e Profissão, 31(2), 268-283. doi: http://dx.doi. org/10.1590/S1414-98932011000200006

Vázquez, A. S. (1999). Ética. Rio de Janeiro: Civilização Brasileira.

Verani, S. (1994). Alianças para a liberdade. In L. M. T. Brito. Psicologia e instituições de direito: a prática em questão (pp. 5-9). Rio de Janeiro: ERJ; CRP-05. 